\title{
A Importância da Reflexão no Estágio Curricular na Licenciatura em Enfermagem: Uso de Heurísticos
}

\author{
Débora Rodrigues Vaz1, Mauricio Pietrocola Pinto de Oliveira², Denise Maria de Almeida1, \\ Cláudia Prado33, Alfredo Almeida Pina-Oliveira³, Maria de Fatima Prado Fernandes 3 \\ ${ }^{1}$ Programa de Pós-Graduação em Gerenciamento em Enfermagem da Escola de Enfermagem da Universidade \\ de São Paulo \\ Departamento de Metodologia de Ensino e Educação Comparada da Faculdade de Educação da \\ Universidade de São Paulo \\ ${ }^{3}$ Departamento de Orientação Profissional da Escola de Enfermagem da Universidade de São Paulo
}

* Autora para correspondência: debora.vaz@usp.br

\section{RESUMO}

O presente artigo apresenta o desenvolvimento de um heurístico para estimular a reflexão sobre o clima emocional e as dimensões relacional e comunicacional no estágio curricular supervisionado no curso de Licenciatura em Enfermagem da Escola de Enfermagem da Universidade de São Paulo. A metodologia consistiu na tradução, adaptação, reorganização e desenvolvimento de um heurístico com foco na vivência durante os estágios curriculares supervisionados da Licenciatura em Enfermagem. O heurístico é composto por 53 indagações reflexivas que evidenciam quatro dimensões: o relacionamento entre o licenciando e o professor supervisor; entre o licenciando e os funcionários das instituições de saúde; entre os licenciandos e os estudantes; e entre os próprios licenciandos. $\mathrm{O}$ uso do heurístico pode contribuir para a reflexão sobre o estágio curricular supervisionado e auxiliar o licenciando a (re)pensar seu desempenho com vistas ao seu aprimoramento pessoal e docente a partir da análise de suas próprias emoções, relações interpessoais e estratégias de comunicação que podem interferir em seu processo de ensino e de aprendizagem.

Palavras-chave: Educação Superior; Enfermagem; Estágio; Aprendizagem; Heurístico.

\begin{abstract}
This paper presents a heuristic creation process in order to encourage reflection on interpersonal relations and their emotional and communicational dimensions during Nursing Baccalaureate supervised internship related to Licensed Practical Nurses' preparation. We performed a translation, adaptation, reorganization and development of a heuristic which focuses on experiential learning during Nursing Baccalaureate's internship. A reflexive 53 item-instrument was yielded evincing four dimensions: Nursing student-supervisor teacher relationships, Nursing student-health services workers relationships, Nursing student-Licensed Practical Nursing students relationships and Nursing students relationships among themselves. The use of heuristic may contribute to relevant reflection regarding Nursing Baccalaureate's internship and it helps Nursing students to (re) think their performance with the purpose of achieving personal and teaching skills improvement from their own emotions, interpersonal relationships and communicative strategies analysis influencing their teaching and learning process.
\end{abstract}

Keywords: Higher Education; Nursing; Internship; Learning; Heuristic.

\section{Introdução}

As exigências do mercado de trabalho em consonância com as Diretrizes Curriculares Nacionais do curso de graduação em Enfermagem e a Lei de Diretrizes e Bases da Educação Nacional (LDB) têm levado profissionais da saúde e da edu- cação a investirem em projetos que contribuam para a formação de docentes com competências para atuar de forma crítico-reflexiva e responsável na educação profissional de nível técnico em Enfermagem. Espera-se que o docente, além do domínio de conhecimentos específicos, desenvol- 
va uma capacidade e uma atitude crítica que lhe permitam avaliar seu trabalho, suas opções e suas decisões (LOBO NETO, 2002).

\section{Formação Reflexiva}

Ser professor reflexivo implica ter a consciência de uma capacidade de pensamento e reflexão que caracteriza o ser humano, não como um mero reprodutor de ações, mas como capaz de ser criativo, agindo de forma inteligente e flexível, situada e reativa diante de situações muitas vezes incertas e imprevistas (ALARCÃO, 2010).

Apesar de a capacidade de reflexão ser inata ao ser humano, é comprovada a dificuldade que as pessoas, em qualquer idade, revelam ao porem em prática os mecanismos reflexivos, sendo necessário um esforço muito grande para passar do nível meramente descritivo ou narrativo para um nível onde se buscam "interpretações articuladas e justificadas e sistematizações cognitivas" (Idem, ibidem).

O contexto social amplo e os caminhos que conduzem às práticas reflexivas devem ser compreendidos, e essa compreensão deve ser posta como "possibilidade a ser construída e elaborada nos cursos de formação, de modo a levar os estudantes a explicitarem o seu pensamento e as suas atitudes". O pensamento reflexivo e a capacidade investigativa precisam ser instigados, cultivados e requerem condições favoráveis para o seu surgimento (BARREIRO \& GEBRAN, 2006).

É desejável que o docente inicie na formação o processo de desenvolvimento de sua capacidade de reflexão sobre a prática, salientando-se ainda a necessidade de uma "prática formativa continuada e em serviço que se articule à formação reflexiva do professor" (NADAL, 2005).

\section{O Estágio Curricular na Licenciatura em Enfermagem}

Segundo a Indicação CEE 64/2007, para exercer a docência na educação profissional de nível técnico em Enfermagem, que compreende a Qualificação em Auxiliar de Enfermagem e a Habilitação em Técnico de Enfermagem, é exigida do enfermeiro a formação pedagógica que se concretiza nos cursos de Licenciatura em Enfermagem.

Na trajetória de formação docente, o enfermeiro licenciando, como parte do estágio curricular realizado em escolas técnicas, acompanha futuros auxiliares e técnicos de enfermagem na prestação de cuidados a pacientes em diferentes instituições de saúde.

Nessas instituições o licenciando precisa relacionar-se com o professor supervisor, responsável pela condução do estágio, pela supervisão e avaliação dos futuros auxiliares e técnicos e também pela avaliação do seu desempenho, e nem sempre com o necessário preparo pedagógico para exercer esse papel. Também precisa se relacionar com os futuros auxiliares e técnicos, pelos quais, muitas vezes, jamais deixará de ser visto como um estagiário, e com os colaboradores da instituição de saúde, pacientes e seus familiares, o que denota a complexidade das relações nesse contexto.

Dessa maneira, é importante que o futuro docente, por meio da reflexão, desenvolva atitudes de acolhimento e de compreensão do outro, visto que as interações entre estudantes, estudante/ docente, estudante/colaboradores são variáveis que interferem na eficácia da aprendizagem, facilitada quando a relação interpessoal é sólida (CARVALHO et al., 1999).

Em pesquisa que avaliou as narrativas contidas em portfólios de licenciandos do curso de Licenciatura em Enfermagem de uma instituição de São Paulo, quanto a facilidades e dificuldades associadas às características do campo de estágio, observou-se a predominância de dificuldades vinculadas às dimensões relacional e comunicacional (VAZ, 2013).

Um olhar cuidadoso às falas evidenciou que as dificuldades envolveram a falta de acolhimento e receptividade por supervisores, estudantes e equipe multiprofissional; pouca disponibilidade ou falta de vontade para auxiliar em vários aspectos, principalmente por parte da equipe de enfermagem das instituições hospitalares; falta de flexibilidade, de disponibilidade para ajudar e ensinar, de paciência e tolerância por parte dos professores 
supervisores; falta de entrosamento entre professores supervisores, estudantes e licenciandos; forte relação de subordinação entre professores supervisores e estudantes/licenciandos; e falta de comunicação de uma forma geral (Idem, ibidem).

Há dois grupos de relações aqui bem definidos: a relação entre a equipe multiprofissional da instituição e o supervisor/licenciando/estudante e a relação entre professor/supervisor e estudantes/ licenciandos. No primeiro, a equipe multiprofissional encontra-se em situação de trabalho (assistência ao paciente), e não faz parte da sua função diária participar das situações de aprendizado dos estudantes/licenciandos, mas se faz necessário que ela colabore, pois o paciente está sob sua responsabilidade. A referida equipe assinala que não têm tempo disponível para o estudante/licenciando, que dividir tarefas com eles atrapalha o andamento de seu plantão etc. O segundo envolve relação professor/estudante/licenciando e toda a cultura didática que a permeia, como acontece dentro da sala de aula.

Apesar de todos esses indivíduos já terem passado, em algum momento de sua vida, por experiências nas relações entre professores e estudantes, e de, questionados, perceberem quais foram as dificuldades e o que gostariam que fosse diferente, a maioria deles parece não se esforçar para fazer diferente diante de novas situações. Tal fato traz à tona uma necessidade, ou mesmo uma curiosidade, de entender por que isso acontece. Sem dúvida há muito mais reprodução dessas vivências do que transformação. Essa problemática pode ser analisada à luz da dualidade estrutural entre transformação e reprodução numa perspectiva cultural.

\section{Reprodução e Transformação Cultural}

Cultura é uma categoria da vida social que pode ser definida de diferentes maneiras. $\mathrm{O}$ conceito que aqui mais se relaciona com o exposto é o de cultura para além de um sistema de símbolos e significados, mas como um corpo de práticas, crenças, instituições, costumes, hábitos, mitos etc., construída por seres humanos e passada de geração em geração (SEWELL, 2005).
Trata-se de uma esfera de atividades práticas desempenhadas por uma determinada coletividade, que envolvem ações, performances, relações de poder, luta, contradições e mudanças. Os sentidos e ações de tais práticas estão relacionados com um sistema de valores, significados, símbolos e interpretações compartilhados pelos indivíduos que constituem o grupo. A partir desse conceito a cultura está então sujeita a contingências, transformações.

Essa disponibilidade à transformação pode ser fundamentada pela teoria da estruturação proposta por Giddens (1984), que sustenta que toda ação humana realizada dentro de uma determinada estrutura social é regida por um conjunto de sistemas de recursos e esquemas, os quais podem ser alterados pela ação humana. As estruturas não são a prática em si, mas os princípios que regem a ação. São resultado de uma evolução contínua e matriz do processo de interação social. A estrutura molda as práticas das pessoas, mas é também por estas constituídas (e reproduzidas).

Esse "poder" de transformação da estrutura pelo indivíduo, denominado agency, refere-se então à capacidade inerente ao ser humano de exercer certo grau de controle sobre as relações sociais nas quais está inserido/envolvido (SEWELL, 2005).

Retomando a problemática do estágio, percebe-se que há uma reprodução dos mesmos comportamentos pelos indivíduos, que se utilizam de recursos e esquemas para manter a estrutura. Manter a estrutura garante aos professores, por exemplo, a posição superior, sem terem de ouvir as reivindicações dos estudantes, sem tornarem o relacionamento mais horizontal, o que, se alterado, demanda tempo, reflexão, tomada de consciência de seu desempenho e abertura à crítica. Por parte dos funcionários garante, por exemplo, não se envolverem no aprendizado dos estudantes e do licenciando, o que também descarta críticas ao próprio desempenho, uma vez que, diante do diálogo, dúvidas e esclarecimentos sobre os cuidados prestados ao paciente irão aflorar.

Porém, diante da capacidade de agency, o ser humano passa a ser visto como ser cognoscente e 
intencionado que pode monitorar reflexivamente sua ação. Não de forma consciente, discursiva, mas para alcançar determinado objetivo, por exemplo. O ser humano é entendido como ser dotado de capacidade para desenvolver uma atividade intencionada, possuindo não só alguma compreensão do que faz, mas também e principalmente das razões pelas quais o faz (GIDDENS, 1984).

É desejável que o licenciando, durante sua formação, tenha oportunidade de pensar sobre essas questões; de trazer esse poder de transformação para a dimensão discursiva, a fim de transformar sua futura prática pedagógica, favorecendo o desenvolvimento cognitivo e emocional de seus estudantes, melhorando o relacionamento e o clima emocional nos campos de estágio. Para isso é preciso instrumentalizar o licenciando, mostrando ferramentas que o ajudem a refletir e transformar.

\section{Heurístico como Ferramenta para a Reflexão}

Um heurístico é entendido como um "modelo", um exemplo para dar corpo a uma construção social, revelando algumas de suas características, a fim de proporcionar um processo de conhecimento, tomada de consciência dessa construção a qual facilita a reflexão e mudanças relacionadas com aspectos relevantes da vida social (POWIETRZYNSKA, 2014).

Trata-se de uma ferramenta flexível, podendo assumir diferentes formas e propósitos, o que permite sua utilização em diversos contextos. A utilização que nos interessa neste artigo é como ferramenta de intervenção, possibilitando, por meio de indagações reflexivas, que os participantes se tornem conscientes de questões relevantes, suas características e ocorrências relativas. A conscientização dos fatos pode levar à mudança de hábitos (Idem, ibidem).

Em relação ao formato, um heurístico pode assemelhar-se a uma "pesquisa", um "exame", no qual cada questão é acompanhada de uma classificação, que tem a intenção de levar o entrevistado a fazer uma conexão pessoal com cada questão, cada "assunto" abordado (Idem, ibidem).
A intenção não é obter uma avaliação precisa de como a pessoa encara tais situações, mas chamar a atenção para a forma como se dá a conscientização, a tomada de consciência de tais questões. O objetivo é criar uma oportunidade para a autorreflexão em relação a uma série de questões que evidenciam o que ser consciente pode significar (Idem, ibidem).

Tais questões podem fazer o participante pensar e, diante de dilemas, aspectos relacionados com as crenças do professor, a história dos sujeitos implicados, a percepção da situação, os objetivos, as alternativas de ação disponíveis e as estratégias de resolução podem ser acionados (MADEIRA \& LIMA, 2008). São transformações dessa ordem que põem em questão os pressupostos da racionalidade técnica no modelo de formação, provocando rupturas nesse processo, conduzindo à emergência de concepções alternativas sobre o papel do professor, consolidando-o como prático reflexivo (Idem, ibidem).

\section{Objetivo}

Apresentar o desenvolvimento de um heurístico para estimular a reflexão sobre o clima emocional e as dimensões relacional e comunicacional no estágio curricular supervisionado no curso de Licenciatura em Enfermagem da Escola de Enfermagem da Universidade de São Paulo.

\section{Metodologia}

O heurístico aqui apresentado, desenvolvido na disciplina de pós-graduação EDM5143 - Ensino, Aprendizagem e Cultura Didática: Complexidade Escolar e Análise Multi-Lógica (Faculdade de Educação - USP) -, teve como base o modelo elaborado por Powietrzynska (2014) (Quadro 1), que foi contextualizado em um ambiente educacional e inclui características de reflexão do ambiente de ensino-aprendizagem. Baseado na escala de Likert de cinco pontos, esse instrumento possibilita a avaliação da frequência dos sentimentos vivenciados: 5 $=$ muitas vezes ou sempre; $4=$ frequentemente; $3=$ às vezes; $2=$ raramente; $1=$ quase nunca ou nunca.

Ao se considerar a capacidade de o heurístico ser adaptado - o que alguns autores chamam 


\section{Mindfulness in Education Heuristic}

For each characteristic circle the numeral that best reflects your current state of mindfulness in this class. As necessary, provide contextual information that applies to your rating. During this class:

1. I am curious about my feelings as they rise and fall.

2. I find words to describe the feelings I experience.

3. I identify distracting thoughts but let them go (without them influencing future action).

4. I am not hard on myself when I am unsuccessful.

5. I recover quickly when I am unsuccessful.

6. I pay attention to my moment-to-moment sensory experiences.

7. I am aware of the relationship between my emotions and breathing pattern.

8. I am aware of changes in my emotions and pulse rate.

9. I maintain a positive outlook.

10. I can tell when something is bothering the teacher.

11. I can tell when something is bothering other students.

12. The way in which I express my emotions depends on what is happening.

13. The way in which I express my emotions depends on who is present.

14. I can focus my attention on learning.

15. I feel compassion for myself when I am unsuccessful.

16. I feel compassion for others when they are unsuccessful.

17. When I produce strong emotions I easily let them go.

18. I gauge my emotions from changes in my body temperature.

19. I am aware of others' emotions from characteristics of their voices.

20. I am aware of my emotions being expressed in my voice.

21. I recognize others' emotions by looking at their faces.

22. I am aware of my emotions as they are reflected in my face.

23. My emotions are evident from the way I position and move my body.

24 . The way I position and move my body changes my emotions.

25. I can tell others' emotions from the way they position and move their bodies.

26. I am aware of emotional climate and my role in it.

27. Seeking attention from others is not important to me.

28. Classroom interactions are characterized by winners and losers.

29. I meditate to manage my emotions.

30. I use breathing to manage my pulse rate.

31. I use breathing to manage my emotions.

Quadro 1 - Heurístico desenvolvido por Powietrzynska (2014).

de "shape shifter" (PIETROCOLA, s.d.) -, o heurístico descrito foi traduzido para a Língua Portuguesa, adaptado e reorganizado, visando a uma melhor adequação à vivência nos estágios curriculares da Licenciatura em Enfermagem.

Foram retirados os itens $6,7,8,17,18,24,27$, 30 e 31, pois alguns continham ideias já apresentadas e outros se relacionavam à identificação de alterações corporais como temperatura, frequência cardíaca e respiratória, alterações estas importantes, mas fora do foco do presente estudo.

\section{Resultados e discussão}

O resultado do estudo é o heurístico apresentado no Quadro 2, composto por 53 itens.

A inclusão dos itens 22 a 42 e 44 a 53 no heurístico é justificada na sequência. Os itens 22 a 31 evidenciam o relacionamento entre licenciando e professor supervisor. Essa relação precisa favorecer a aprendizagem e oportunizar experiências relacionadas com o desenvolvimento pessoal e profissional do licenciando, uma vez que a supervisão dos estudantes não pode ser concebida apenas como uma 


\section{Heurístico: reflexão nos estágios na Licenciatura em Enfermagem}

Para cada característica circule o numeral que melhor reflete seu estado atual de conscientização neste período. Quando necessário, fornecer informações contextuais que se aplicam a sua classificação. $(5=$ muitas vezes ou sempre; $4=$ frequentemente; 3 = às vezes; 2 = raramente e 1 = quase nunca ou nunca)

Durante o período de estágio:

1. Eu tenho curiosidade sobre os meus sentimentos à medida que eles se alteram.

2. Eu encontro palavras para descrever os sentimentos que experiencio.

3. Eu percebo meus pensamentos, mas deixo-os ir (sem que eles influenciem ações futuras).

4. Eu não sou exigente comigo mesma quando as coisas não dão certo.

5. Eu me recupero rapidamente diante de um fracasso.

6. Eu mantenho uma perspectiva positiva.

7. A maneira pela qual eu expresso minhas emoções depende do que está acontecendo.

8. A maneira pela qual eu expresso minhas emoções depende de quem está presente.

9. Eu consigo focar minha atenção no aprendizado.

10. Eu sinto compaixão por mim mesmo quando não tenho êxito / não sou bem-sucedido.

11. Eu sinto compaixão pelos outros quando eles não são bem-sucedidos.

12. Eu tomo ciência das emoções dos outros pelas características de suas vozes.

13. Eu estou ciente das minhas emoções sendo expressas na minha voz.

14. Eu reconheço as emoções dos outros, olhando para suas faces.

15. Eu estou ciente das minhas emoções e como elas se refletem em minha face.

16. Minhas emoções são evidentes a partir da maneira que eu me posiciono e mexo meu corpo.

17. Eu posso perceber as emoções dos outros pela maneira como eles se posicionam e movem seus corpos.

18. Estou ciente do clima emocional e do meu papel nele.

19. Interações no ambiente de estágio são caracterizadas por vencedores e perdedores.

20. Eu uso a reflexão para gerir as minhas emoções.

21. Eu percebo quando algo está incomodando o professor supervisor.

22. Eu percebo que o professor supervisor ouve atentamente minhas dúvidas e sentimentos.

23. Eu ouço atentamente o que o supervisor tem a me dizer, até mesmo sobre meu desempenho.

24. Eu tento me colocar no lugar do professor supervisor.

25. Eu percebo que o professor supervisor tenta se colocar no meu lugar.

26. Eu estou aberto às sugestões do professor supervisor.

27. Eu percebo que o professor supervisor está aberto às minhas sugestões.

28. O professor supervisor me deixa conduzir situações de aprendizagem.

29. O professor supervisor me acompanha e me auxilia ativamente nas atividades com os estudantes.

30. Eu me espelho na maneira como o professor supervisor conduz as situações de aprendizagem.

31. Eu percebo que o modo como o professor se relaciona com os estudantes influencia na aprendizagem deles.

32. Eu percebo que os funcionários da instituição têm prazer em colaborar e dividir seus conhecimentos com o grupo.

33. Eu percebo que os funcionários têm paciência com o grupo.

34. Eu me sinto acolhida pelos funcionários.

35. Eu percebo que os estudantes se sentem acolhidos pelos funcionários.

36. Eu percebo que o professor supervisor se sente acolhido pelos funcionários.

37. Estou aberto às sugestões dos funcionários.

38. Eu percebo que os funcionários estão abertos às nossas sugestões.

39. Eu tento me colocar no lugar do funcionário.

40. Eu percebo que os funcionários tentam se colocar nos nossos lugares.

41. Eu percebo quando o comportamento do funcionário é influenciado por fatores externos ao ambiente hospitalar.

42. Eu tenho medo que o funcionário me trate mal.

43. Eu percebo quando algo está incomodando os outros licenciandos.

44. Eu percebo quando os outros licenciandos estão em dificuldade.

45. Eu ofereço ajuda aos licenciandos em dificuldades.

46. Os outros licenciandos me oferecem ajuda quando estou com dificuldades.

47. Eu percebo o contexto social dos estudantes.

48. Ao avaliar o estudante eu começo por suas facilidades.

49. Eu percebo que os estudantes aceitam de bom grado as atividades propostas por mim.

50. Eu percebo que os estudantes me respeitam e acatam minhas orientações da mesma forma que fazem com o professor supervisor.

51. Eu demonstro disponibilidade para auxiliar os estudantes.

52. Eu percebo que os estudantes tentam se colocar no meu lugar.

53. Eu tento me colocar no lugar dos estudantes.

Quadro 2 - Heurístico: reflexão nos estágios na Licenciatura em Enfermagem. 
estreita relação de ajuda, ela precisa incluir a noção de continuidade, reflexão e retroalimentação (SIMÕES \& GARRIDO, 2007).

Para Alarcão (2010), a "supervisão é uma atividade de natureza psicossocial, de construção intra e interpessoal, fortemente enraizada no conhecimento do eu, do outro e dos contextos em que os atores interagem", especificamente nos contextos formativos. Deve basear-se na "interação entre o pensamento e a ação, com o objetivo de dar sentido ao vivido e ao conhecido, isto é, de compreender melhor para melhor agir" e deve propiciar "o desenvolvimento de capacidades, atitudes e conhecimentos e o contributo destes para a competência profissional, essa de natureza integrada e holística".

Supervisionar, na visão da autora, consiste em uma atividade mediadora dos processos de aprendizagem e de desenvolvimento do formando e do supervisor, podendo ser facilitada ou inibida de acordo com a natureza da relação estabelecida. Para que cada sujeito seja estimulado a progredir e criar seu estilo próprio de intervenção, é fundamental que as interações se desenvolvam num ambiente de confiança e interajuda afetiva e cognitivamente estimulante, no qual o supervisor também está em desenvolvimento (ALARCÃO, 2010).

Assim, cabe ao supervisor "a criação de um ambiente de colaboração em que a liberdade para fazer escolhas seja promovida e em que o formando seja apoiado no desenvolvimento de uma linguagem pessoal e profissional própria que fundamente suas escolhas" (GRILO \& MACHADO, 2005).

Os itens 32 a 42 evidenciam o relacionamento com os funcionários (incluindo a equipe de saúde) das instituições onde ocorrem os estágios curriculares: hospitais, clínicas, Unidade Básica/Posto de saúde.

Em pesquisa sobre experiências vivenciadas por estudantes no estágio curricular de um curso técnico em enfermagem (STUTZ \& JANSEN, 2006), concluiu-se que a participação dos professores e dos funcionários tem importante papel na redução da ansiedade e no fortalecimento da autoconfiança e da autoestima dos estudantes, auxiliando-os a enfrentarem os desafios que a aprendizagem prática da enfermagem representa nos contatos iniciais com o mundo do trabalho. Se lidar com a complexidade característica do ambiente de trabalho é difícil para um funcionário experiente, mais ainda para um estudante recém-chegado (Idem, ibidem).

Na referida pesquisa, foram constatadas dificuldades no relacionamento dos estudantes com os funcionários junto aos quais atuam diretamente na instituição hospitalar, na fase inicial do processo de aprendizagem prática, tais como instabilidade de humor, resistência dos funcionários a orientarem professores e estudantes, indiferença por parte de alguns funcionários e até recusa em acompanharem o estagiário. Destaca-se a importância de trabalhar as relações interpessoais no cotidiano hospitalar, porém isso demanda, a princípio, a elucidação dos fatores que contribuem para o surgimento dos problemas (Idem, ibidem).

É preciso reconhecer ainda que as dificuldades pelas quais muitas instituições passam, como, por exemplo, cortes de verbas públicas, quadro profissional limitado, insalubridade, avanços tecnológicos e deficiência de recursos materiais, entre outras, podem gerar insegurança e insatisfação no trabalho, levando a comportamentos de desrespeito entre os próprios funcionários (BACKES \& LUNARDI, 2006).

Então, a formação de vínculos saudáveis contribui para a diminuição do estresse causado pelas novas experiências, para o controle da ansiedade diante das dificuldades encontradas e para a construção da identidade profissional, a fim de que o estudante se reconheça como parte do grupo existente e não alguém à margem dele (STUTZ \& JANSEN, 2006).

Os itens 44 a 46 evidenciam o relacionamento entre os licenciandos, que podem fazer estágio no mesmo campo.

Acredita-se que os formandos possam estabelecer entre si relações supervisivas, que facilitem a cada um o processo de autoformação, com as vantagens da ausência de barreiras, num clima de suporte, de ajuda crítica, de solidariedade e de desenvolvimento mútuo, consciente e partilhado, enriquecendo a formação (GRILO \& MACHADO, 2005; SÁ-CHAVES, 2000). Porém, deve-se consi- 
derar que essas relações podem ser influenciadas pelo nível de desenvolvimento pessoal e profissional de cada um, pelas experiências anteriores e pelos contextos socioculturais nos quais essas experiências ocorreram (SÁ-CHAVES, 2000).

Os itens 47 a 53 evidenciam o relacionamento entre o licenciando e os estudantes, uma vez que estes têm dificuldade em perceber e acolher o licenciando no desempenho do papel docente e, para aproximá-los, são necessárias paciência, empatia e atitudes de acolhimento.

Contudo, é importante que o licenciando entenda o papel central do estudante na ação educativa e mobilize seus conhecimentos em relação às abordagens pedagógicas para tornar essa relação mais horizontal, mais humanizada, conquistando e desempenhando seu papel de mediador no processo de ensino-aprendizagem e oportunizando ao estudante ser mais ativo e reflexivo.

Em suma, vale salientar que a "identidade é o lugar de lutas e conflitos, um espaço no qual se constroem e reconstroem modos de ser e de estar na profissão", e assim a

construção da identidade profissional se faz, também, a partir do sentido que o profissional confere ao seu trabalho, das suas crenças e motivações, das suas disposições pessoais, de tudo o que se constitui como lugar de "afirmação" do que se quer, do que não se quer e do que se pode, enquanto professor (MOREIRA, 2010).

\section{Conclusão}

Acredita-se que o heurístico desenvolvido possibilitará a reflexão sobre o clima emocional e as dimensões relacional e comunicacional que permeiam as relações nos estágios curriculares dos cursos de Licenciatura em Enfermagem. Poderá ainda nortear a reflexão de licenciandos de diferentes áreas do conhecimento, auxiliando-os a (re) pensarem seu desempenho com vistas ao aprimoramento contínuo, tanto na formação inicial quanto na futura prática profissional.

O heurístico será aplicado pelos docentes do curso em dois momentos (durante e após a realização do estágio). Os dados obtidos serão analisados pelos docentes e compartilhados com os licenciandos para discussão e busca de estratégias de aprimoramento do estágio quanto ao relacionamento inter e intrapessoal. Além disso, servirão para estabelecer critérios de escolha dos campos de estágio e para facilitar a comunicação instituição de ensino/campo a respeito da acolhida aos licenciandos, visando a melhorar o clima do estágio para todos os seus atores.

Entende-se que a melhoria nas relações interpessoais depende de todos os sujeitos envolvidos e que, obviamente, apenas a reflexão por parte dos licenciandos não garante o aprimoramento dessas relações, mas pode ajudá-los no desenvolvimento de estratégias de comunicação, de resolução de conflitos e de construção de parcerias mais efetivas, a fim de promoverem transformações na realidade na qual estiverem inseridos.

Espera-se que o licenciando, a partir de tal vivência, possa tornar-se um professor e/ou supervisor mais compreensivo e ativo em relação às dificuldades que os funcionários dos campos de estágio enfrentam e às necessidades dos estudantes.

À guisa de síntese, o presente estudo pretende contribuir para o avanço na lacuna do conhecimento relativo à utilização de instrumentos de reflexão relacionados com a construção da identidade docente. Assim, a próxima etapa do estudo consistirá na aplicação do heurístico a licenciandos de Enfermagem e, por extensão, a outros cenários educacionais (bacharelados e cursos tecnológicos) que valorizem a formação reflexiva.

\section{Referências Bibliográficas}

ALARCÃO, I. Professores Reflexivos em uma Escola Reflexiva. 7. ed. São Paulo: Cortez, 2010. Coleção Questões da Nossa Época, 8.

BACKES, D. S.; LUNARDI, V. L. \& LUNARDI FILHO, W. D. "A Humanização Hospitalar como Expressão da Ética". Rev. Latino-Am. Enfermagem, vol. 14, n. 1, 2006. Disponível em: <http://www.scielo.br/pdf/ rlae/v14n1/v14n1a18.pdP $>$. Acessado em abr. 2017.

BARREIRO, I. M. F. \& GEBRAN, R. A. Prática de Ensino e Estágio Supervisionado na Formaşão de Professores. São Paulo: Avercamp, 2006. 
CARVALHO, M. D. B. et al. "Expectativas dos Alunos de Enfermagem frente ao Primeiro Estágio em Hospital". Rev. Esc. Enferm., USP, vol. 33, n. 2, 1999. Disponível em: <http:// www.scielo.br/scielo.php? script $=$ sci_arttext\&pi$\mathrm{d}=$ S0080-62341999000200012\&lng=en\&nrm=iso $>$. Acessado em abr. 2017.

GIDDENS, A. The Constitution of Society: Outline of the Theory of Structuration. Cambridge: Polity Press, 1984.

GRILO, J. \& MACHADO, C. "'Portfólios' Reflexivos na Formação Inicial de Professores de Biologia e Geologia: Viagens na Terra do Eu". In: SÁ-CHAVES, I. (org.). Os "Portfólios" Reflexivos (Também) Trazem Gente Dentro: Reflexões em Torno do Seu Uso na Humanização dos Processos Educativos. Porto: Porto Editora, 2005.

LOBO NETO, F. J. S. "Ser Professor: Necessidade de Formação Profissional Específica". Formasão, vol. 2, n. 4, 2002. Disponível em: $>$ http://bvsms.saude.gov.br/bvs/publicacoes/profae/Revista2004.pd† $>$. Acessado em abr. 2017.

MADEIRA, M. Z. A. I. \& LIMA, M. G. S. B. "A Prática de Ensinar: Dialogando com as Professoras de Enfermagem". Rev. Bras. de Enf., vol. 61, n. 4, 2008. Disponível em: <http://www.scielo.br/scielo.php?pi$\mathrm{d}=$ S0034-71672008000400008\&script=sci_abstract\&tl$\mathrm{ng}=\mathrm{pt}>$. Acessado em abr. 2017.

MOREIRA, J. Portfólio do Professor: o Portfólio Reflexivo no Desenvolvimento Profissional. Porto: Porto, 2010.

NADAL, B. G. "Possibilidades para a Formação de Professores Prático-Reflexivos através de Iniciativas de Formação Contínua: Espaços de Intersecção". In: RIBAS, M. H. (org.). Formaşão de Professores: Escolas, Práticas e Saberes. Ponta Grossa: UEPG, 2005.
PIETROCOLA, M. "A Heuristic for Mindfulness in Innovative Education". In: POWIETRZYNSKA, M. \& TOBIN, K. Mindfulness in Education. Rotterdam: Sense Publishers, [s.d.] (In press).

POWIETRZYNSKA, M. Promoting Wellness Through Mindfulness - Based Activities. Tese. New York, The City University of New York, 2014. Disponível em: <http:// works.gc.cuny.edu/etd/268/>. Acessado em abr. 2017.

SÁ-CHAVES, I. S. C. Portfólios Reflexivos: Estratégia de Formação e de Supervisãa. Aveiro: Universidade de Aveiro, 2000.

SEWELL, W. H. "A Theory of Structure: Duality, Agency and Transformation". In: . Logics of History: Social Theory and Social Transformation. Chicago, University of Chicago Press, 2005.

SIMÕES, J. F. F. L. \& GARRIDO, A. F. S. "Finalidade das Estratégias de Supervisão Utilizadas em Ensino Clínico de Enfermagem". Texto Contexto Enferm., vol. 16, n. 4, 2007. Disponível em: <http://www.scielo.br/ pdf/tce/v16n4/a03v16n4.pdf $>$. Acessado em abr. 2017.

STUTZ, B. L. \& JANSEN, A. C. "Ensino Técnico na Área da Saúde: os Desafios do Processo de Aprendizagem". Psicol. Esc. Educ., vol. 10, n. 2, 2006. Disponível em: <http://www.scielo.br/scielo.php?script=sci_arttext\&pid=S1413-85572006000200005\&lng=pt $>$. Acessado em abr. 2017.

VAZ, D. R. Prática Pedagógica Reflexiva de Licenciandos de Enfermagem: o Portfólio como Instrumento. Dissertação (Mestrado em Enfermagem), Escola de Enfermagem, Universidade de São Paulo, 2013. Disponível em: $<$ http://www.teses.usp.br/teses/disponiveis/7/7140/tde12062013-104819/>. Acessado em abr. 2017. 